\title{
Gestational lipid profile as an early marker of metabolic syndrome in later life: a population-based prospective cohort study
}

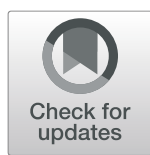

Maria C. Adank 1,2, Laura Benschop ${ }^{1,2}$, Sophia P. van Streun 1,2, Anna M. Smak Gregoor ${ }^{1,2}$, Monique T. Mulder ${ }^{3}$, Eric A. P. Steegers ${ }^{1}$, Sarah Schalekamp-Timmermans ${ }^{1,2}$ and Jeanine E. Roeters van Lennep ${ }^{3^{*}}$

\begin{abstract}
Background: In pregnancy lipid levels increase with gestation resembling an atherogenic lipid profile. Currently it is unclear whether gestational lipid levels are associated with an adverse cardiovascular risk profile later in life. The aim of this study is to assess the association between gestational lipid levels and lipid levels and prevalence of the metabolic syndrome (MS) six years after pregnancy.

Methods: In plasma of 3510 women from the Generation R Study; a prospective population-based cohort, we measured lipid levels (total cholesterol, triglycerides and high-density lipoprotein cholesterol [HDL-c]), and lowdensity lipoprotein cholesterol (LDL-C), remnant cholesterol and non-HDL-c were calculated in early pregnancy (median 13.2 weeks, 90\% range [10.5 to 17.1]) and six years after pregnancy (median 6.5 years, 90\% range [6.2 to 7.8]). MS was assessed six years after pregnancy according to the NCEP/ATP3 criteria. We also examined the influence of pregnancy complications on these associations.

Results: Gestational lipid levels were positively associated with corresponding lipid levels six years after pregnancy, independent of pregnancy complications. Six years after pregnancy the prevalence of MS was 10.0\%; the prevalence was higher for women with a previous placental syndrome (13.5\%). Gestational triglycerides and remnant cholesterol in the highest quartile and $\mathrm{HDL}-\mathrm{c}$ in the lowest quartile were associated with the highest risk for future MS, independent of smoking and body mass index.

Conclusions: Gestational lipid levels provide an insight in the future cardiovascular risk profile of women in later life. Monitoring and lifestyle intervention could be indicated in women with an unfavorable gestational lipid profile to optimize timely cardiovascular risk prevention.
\end{abstract}

Keywords: Pregnancy, Metabolic syndrome, Lipoproteins, HDL, Triglycerides, Cholesterol, LDL, Placental syndrome

\footnotetext{
* Correspondence: j.roetersvanlennep@erasmusmc.nl

${ }^{3}$ Department of General Medicine, Erasmus MC, University Medical Centre Rotterdam, PO Box 2040, 3000 CA Rotterdam, The Netherlands

Full list of author information is available at the end of the article
}

C C The Author(s). 2020 Open Access This article is licensed under a Creative Commons Attribution 4.0 International License, which permits use, sharing, adaptation, distribution and reproduction in any medium or format, as long as you give appropriate credit to the original author(s) and the source, provide a link to the Creative Commons licence, and indicate if changes were made. The images or other third party material in this article are included in the article's Creative Commons licence, unless indicated otherwise in a credit line to the material. If material is not included in the article's Creative Commons licence and your intended use is not permitted by statutory regulation or exceeds the permitted use, you will need to obtain permission directly from the copyright holder. To view a copy of this licence, visit http://creativecommons.org/licenses/by/4.0/ The Creative Commons Public Domain Dedication waiver (http://creativecommons.org/publicdomain/zero/1.0/) applies to the data made available in this article, unless otherwise stated in a credit line to the data. 


\section{Background}

Pregnancy has been proposed as a natural 'stress test' to predict the risk of cardiovascular disease (CVD) later in life [1]. The long-term effect of high blood pressure during pregnancy has been well established [2-6]. Women who develop a hypertensive disorder of pregnancy such as gestational hypertension or pre-eclampsia have a 2-8 times higher risk of developing chronic hypertension, metabolic syndrome and CVD later in life compared to women with an uncomplicated pregnancy $[3,7-11]$. Less is known about the long term cardiovascular effect of gestational lipid levels.

In pregnancy lipid levels rise, leading to $30 \%$ higher levels of cholesterol, triglycerides and LDL-c at the end of the 3rd term [12-15]. The gestational lipid profile therefore shows resemblance to an atherogenic lipid profile. After delivery, lipid levels in general normalize to prepregnancy levels within three to four months [16-18].

Previously it has been shown that women with an adverse gestational lipid profile have an increased risk of gestational hypertension and pre-eclampsia [19, 20]. The other way around, women with a hypertensive disorder of pregnancy also show a more atherogenic lipid profile six years after pregnancy than women with a previous normotensive pregnancy which may contribute to their increased CVD risk in later life [21].

Currently, it is unknown whether the gestational lipid profile, similar to gestational blood pressure, may provide a glimpse of the future cardiovascular health. Moreover it is unknown if body mass index (BMI) is the main driver for the association between gestational lipid levels and lipid levels years after pregnancy. Therefore, the aim of this study is to assess the association between gestational lipid levels with lipid levels and prevalence of the metabolic syndrome six years after pregnancy and to explore to what extent these associate with smoking and BMI. Moreover, as women with pregnancy complications may have a more adverse lipid profile we assessed the incidence of metabolic syndrome and repeated all analyses in women with and without a pregnancy complicated by the placental syndrome (pre-eclampsia, a child born small-forgestational age and spontaneous preterm birth).

\section{Methods}

\section{Design and study population}

This study was embedded in the Generation R study, an ongoing population-based prospective cohort study from early pregnancy onwards in Rotterdam, the Netherlands [22]. Ethical approval for this study was obtained by the Medical Ethics Committee of the Erasmus University Medical Centre (Erasmus MC), Rotterdam, the Netherlands (MEC-2007-413). For this study, we included women with a live born singleton or twin. We excluded women without available lipid measurements during and/or six years after pregnancy, and women taking lipid lowering medication at intake (Fig. 1). Written informed consent was obtained from all participants. Additional file 2 contains a Strengthening the Reporting of Observational Studies in Epidemiology (STROBE) statement for the current study [23].

\section{Exposure: lipid levels in early pregnancy}

Non-fasting blood samples were obtained via venous puncture in early pregnancy (median 13.2 weeks, 90\% range $[10.5$ to 17.1$])$.

\section{Outcome: lipid levels six years after pregnancy}

Non-fasting blood samples were obtained via venous puncture six years after pregnancy (median 6.5 years, $90 \%$ range [6.2 to 7.8$]$ ). All samples were taken by trained research nurses and stored at the research facility at room temperature for a maximum of three hours, after which they were sent to a dedicated laboratory facility $[22,24]$. Glucose levels, total cholesterol, triglycerides and HDL-c concentrations were measured with the Vital Scientific (Merck) Selectra E Chemistry Analyzer. LDL-c, remnant cholesterol and non-HDL-c were calculated [25]. Details of processing procedures and lipid calculations have been described previously [20, 21, 24].

\section{Outcome: metabolic syndrome}

Systolic blood pressure and diastolic blood pressure were measured six years after pregnancy using a validated Omron 907 automated digital oscillometric sphygmomanometer (OMRON Healthcare Europe BV, Hoofddorp, the Netherlands) [26]. According to the NCEP, ATP III criteria, metabolic syndrome was defined as having three or more of the following parameters: waist circumference $(>88 \mathrm{~cm})$; triglyceride levels $(\geq 150 \mathrm{mg} / \mathrm{dL} /$ $\geq 1.70 \mathrm{mmol} / \mathrm{L}$ ) or drug treatment for elevated triglycerides; HDL-c $(<50 \mathrm{mg} / \mathrm{dL} /<1.30 \mathrm{mmol} / \mathrm{L}$ for women); blood pressure $(\geq 130 / \geq 85 \mathrm{mmHg}$ ) or drug treatment for hypertension, and fasting glucose $(\geq 110 \mathrm{mg} / \mathrm{dL})$ or the use of glucose lowering medication [27]. Non-fasting glucose measured six years after pregnancy $\geq 7.8 \mathrm{mmol} /$ $\mathrm{L}$ was used as a proxy for fasting glucose according to the cut-offs of the International Diabetes Federation. Waist circumference was measured ten years after pregnancy (median 9.7 years, 90\% range [9.5 to 10.3]) at the minimum circumference between the iliac crest and the rib cage and was used as a proxy for waist circumference six years after pregnancy.

\section{Placental syndrome}

Placental syndrome was defined as having pre-eclampsia, a child born small-for-gestational age (SGA) or a spontaneous preterm birth (sPTB) in the index pregnancy. We obtained information on clinically diagnosed preeclampsia from medical records that were cross-checked 


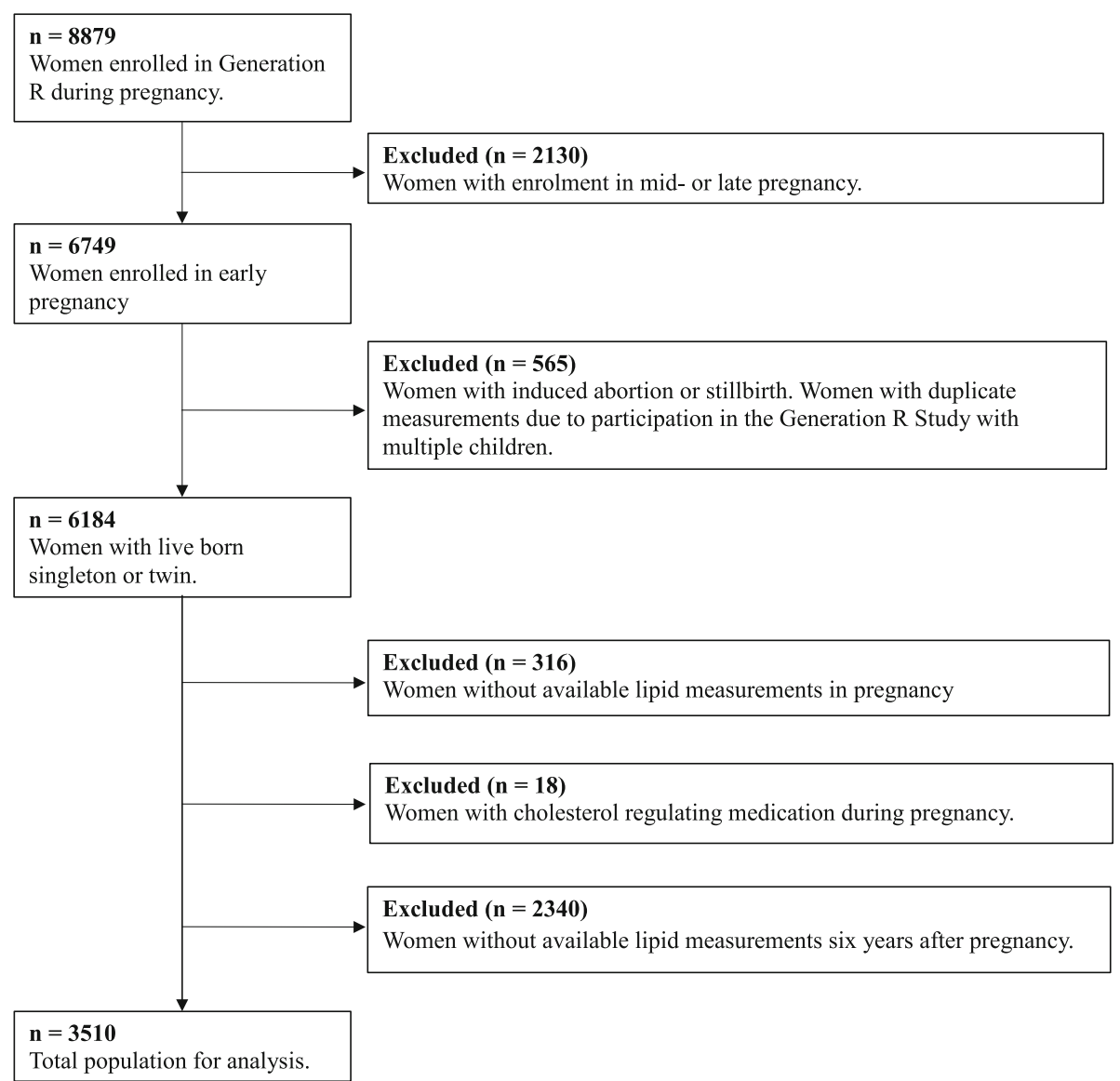

Fig. 1 Flowchart

with the original hospital charts [28]. Pre-eclampsia was defined, using the ISSHP criteria that were in effect at the time of the study, as the development of SBP $\geq 140$ $\mathrm{mmHg}$ and/or a $\mathrm{DBP} \geq 90 \mathrm{mmHg}$ with new-onset proteinuria in a random urine sample and no evidence of a urinary tract infection [29]. Midwife and hospital registries provided information on gestational age at birth, birth weight and child's sex. SGA was defined as a child with a birth weight below the 10th percentile adjusted for gestational age and sex of the child. We defined sPTB as the spontaneous onset of labour before 37 weeks of gestation.

\section{Lifestyle factors and anthropometrics}

Information on characteristics during pregnancy including maternal age, ethnicity, educational level, parity, smoking and information on folic acid supplementation was obtained by questionnaires. Six years after pregnancy, questionnaires were used to obtain information on cholesterol and glucose lowering medication. Height $(\mathrm{cm})$ and weight $(\mathrm{kg})$ were obtained in early pregnancy (median 13.2 weeks of gestational age, 90\% range [10.5 to 17.1] weeks). Height was measured at the research facility without shoes and weight was measured without heavy clothing. Body mass Index (BMI) $\left(\mathrm{kg} / \mathrm{m}^{2}\right)$ was calculated based on measured weight and height. Prepregnancy BMI was obtained from questionnaires. The pre-pregnancy weight and the weight measured at enrolment in early pregnancy were highly correlated (Pearson's correlation coefficient $0.96[P$-value $<.001])$. Therefore, pre-pregnancy weight was used in the analyses.

\section{Statistical analyses}

We examined pregnancy and follow-up characteristics for all women (Table 1). We examined the distribution of lipid levels in early pregnancy for all women with and without the metabolic syndrome six years after pregnancy (Table 2). The presented $P$-values are the result of Student $t$ test for variables with a normal distribution and Mann-Whitney $U$ test for variables with a skewed distribution. Triglyceride and remnant cholesterol levels were $\log$ transformed to achieve a normal distribution. To enable comparison of effect estimates, we constructed SD-scores (SDS) of all lipid levels. We examined the incidence of metabolic syndrome and stratified 
Table 1 Characteristics of the total population $(n=3510)$

\begin{tabular}{|c|c|}
\hline Outcomes in pregnancy & $\begin{array}{l}\text { Mean (SD) or } \\
\text { Median }(90 \% \text { range) }\end{array}$ \\
\hline Age mother, years & $30.3(4.8)$ \\
\hline Gestational age at blood sampling, weeks & $13.2(10.5$ to 17.1$)$ \\
\hline Non-European ethnicity, n (\%) & $1254(35.7)$ \\
\hline Low educational level, n (\%) & $317(9.0)$ \\
\hline Nulliparous, n (\%) & $2226(63.4)$ \\
\hline Pre-pregnancy BMl, kg/m² & 22.7 (18.8 to 32.0) \\
\hline Smoking during pregnancy, n (\%) & $947(27.0)$ \\
\hline No folic acid supplementation, n (\%) & $836(23.8)$ \\
\hline SBP in early pregnancy, mmHg & $116.0(12.4)$ \\
\hline DBP in early pregnancy, $\mathrm{mmHg}$ & $68.5(9.6)$ \\
\hline Total cholesterol, mmol/L & $4.84(0.88)$ \\
\hline Triglycerides, mmol/L & 1.26 (0.72 to 2.33$)$ \\
\hline $\mathrm{LDL}-\mathrm{c}, \mathrm{mmol} / \mathrm{L}$ & $2.43(0.73)$ \\
\hline $\mathrm{HDL}-\mathrm{c}, \mathrm{mmol} / \mathrm{L}$ & $1.79(0.35)$ \\
\hline Remnant cholesterol, mmol/L & 0.57 (0.33 to 1.06$)$ \\
\hline Non-HDL-c, mmol/L & $3.05(0.84)$ \\
\hline Glucose, mmol/L & $4.38(0.85)$ \\
\hline Gestational age at birth, weeks & 40.1 (36.9 to 42.1$)$ \\
\hline Birth weight, g & $3414(558)$ \\
\hline Small-for-gestational age, n (\%) & $350(10.0)$ \\
\hline Spontaneous preterm birth, n (\%) & $125(3.6)$ \\
\hline Pre-eclampsia, n (\%) & $80(2.4)$ \\
\hline \multicolumn{2}{|l|}{ Six years after pregnancy } \\
\hline Interval time, years & $6.5(6.2$ to 7.8$)$ \\
\hline Age mother, years & $37.0(4.8)$ \\
\hline Maternal BMI, kg/m² & 24.4 (19.7 to 35.0$)$ \\
\hline Total cholesterol, mmol/L & $4.87(0.89)$ \\
\hline Triglycerides, mmol/L & 1.14 (0.61 to 2.51$)$ \\
\hline LDL-c, mmol/L & $2.91(0.78)$ \\
\hline $\mathrm{HDL}-\mathrm{c}, \mathrm{mmol} / \mathrm{L}$ & $1.37(0.33)$ \\
\hline Remnant cholesterol, mmol/L & 0.52 (0.28 to 1.13$)$ \\
\hline Non-HDL-c, mmol/L & $3.50(0.89)$ \\
\hline Glucose, mmol/L & $5.47(0.99)$ \\
\hline Waist circumference, cm & $82.8(11.0)$ \\
\hline $\mathrm{SBP}, \mathrm{mmHg}$ & $119.2(12.7)$ \\
\hline $\mathrm{DBP}, \mathrm{mmHg}$ & $70.6(9.9)$ \\
\hline Metabolic syndrome, n (\%) & $350(10.0)$ \\
\hline
\end{tabular}

Data are presented as mean (SD), median ( $90 \%$ range) or number of subjects (valid percentage) depending on normal or skewed distributions. Covariates are imputed. Waist circumference was measured ten years after pregnancy. Abbreviations: SBP, systolic blood pressure; DBP, diastolic blood pressure; LDLc, Low-density lipoprotein cholesterol; HDL-c, High-density lipoprotein cholesterol; BMI, body mass index this by its components (Fig. 3). We imputed missing values in confounders that were used for linear and logistic regression analyses. We used the Markov Chain Monte Carlo multiple imputation procedures to reduce potential bias attributable to missing data [30]. Data were analyzed in each set separately, and pooled estimates from the five imputed data sets were used to report the effect estimates and their 95\% confidence interval. For the multiple imputation procedure we performed ten iterations [31]. In this study $5.0 \%$ of women had missing information on educational level, $1.3 \%$ on ethnicity, $0.5 \%$ on parity, $9.3 \%$ on smoking, $21.3 \%$ on folic acid supplementation and $16.5 \%$ on pre-pregnancy BMI. To relate lipid levels in early pregnancy to lipid levels and metabolic syndrome six years after pregnancy we performed linear and logistic regression analyses (Table 3 and Additional file 1: Table S1). To assess whether the association of lipid levels in early pregnancy and metabolic syndrome was stronger in women with higher concentrations of lipid levels (total cholesterol, triglycerides, LDL-c, remnant cholesterol and non-HDL-c) in early pregnancy and respectively lower levels of HDL-c, lipid levels in early pregnancy were categorized as quartiles and subsequently used as a categorical measure (Fig. 2). Confounders that were included in the regression models were selected based on their associations with the exposure and outcomes of interest and based on previous studies. The selected confounders included: maternal age at intake, gestational age at blood sampling, educational level, ethnicity, parity, smoking, and folic acid supplementation. For the association of gestational lipid levels with lipid levels six years after pregnancy, prepregnancy BMI was additionally added to the regression models. In attempt to exclude the effect of placental syndromes, we examined the incidence of metabolic syndrome in this subgroup of women and repeated all the analyses excluding women with a placental syndrome in their index pregnancy (Fig. 3). A nonresponse analysis was conducted by comparing the characteristics of women included in this study $(n=$ $3510)$ to women without available lipid levels six years after pregnancy $(n=2340)$ (Additional file 1 : Table S2). Statistical analyses were performed using the IBM Statistical Package of Social Sciences version 24.0 for Windows (SPSS Inc., Chicago, IL).

\section{Results}

This study included a total of 3510 women (Table 1). Women were on average 30.3 years old and 13.2 weeks pregnant when they entered the study. $64.3 \%$ had a European ethnicity, $47.1 \%$ was highly educated, $63.4 \%$ was nulliparous at intake and they had on average a prepregnancy BMI of $22.7 \mathrm{~kg} / \mathrm{m}^{2}$. 
Table 2 Lipid distribution in early pregnancy for women with and without the metabolic syndrome six years after pregnancy $(n=3510)$

\begin{tabular}{llll}
\hline & $\begin{array}{l}\text { Without metabolic syndrome } \\
\boldsymbol{n}=\mathbf{3 1 6 0}\end{array}$ & $\begin{array}{l}\text { With metabolic syndrome } \\
\boldsymbol{n}=\mathbf{3 5 0}\end{array}$ & \multicolumn{1}{c}{-value } \\
\hline Total cholesterol, mmol/L & $4.81(0.87)$ & $5.09(0.90)$ & $<0.001$ \\
Triglycerides, mmol/L & $1.22(0.71$ to 2.19$)$ & $1.66(1.00$ to 3.09$)$ & $<0.001$ \\
$\mathrm{LDL}-\mathrm{c}, \mathrm{mmol} / \mathrm{L}$ & $2.41(0.72)$ & $2.68(0.78)$ & $<0.001$ \\
$\mathrm{HDL}-\mathrm{C}, \mathrm{mmol} / \mathrm{L}$ & $1.81(0.34)$ & $1.58(0.33)$ & $<0.001$ \\
Remnant cholesterol, mmol/L & $0.55(0.32$ to 1.00$)$ & $0.75(0.45$ to 1.37$)$ & $<0.001$ \\
Non-HDL-c, mmol/L & $3.00(0.82)$ & $3.50(0.88)$ & $<0.001$ \\
\hline
\end{tabular}

Data are presented as mean (SD) or as median (90\% range) depending on normal or skewed distributions. Differences between groups are tested through a

Students $t$ test or Mann Whitney U test. Abbreviations: LDL-c, low-density lipoprotein cholesterol; HDL-c, high-density lipoprotein cholesterol

\section{Early gestational lipid levels and lipid levels six years postpartum}

Total cholesterol, triglycerides, LDL-c, HDL-c, remnant cholesterol and non-HDL-c levels were positively associated with their corresponding lipid level six years after pregnancy (Additional file 1: Table S1). These associations were independent of pre-pregnancy BMI.

\section{Early gestational lipid levels and metabolic syndrome six years postpartum}

Six years after pregnancy, 350 (10.0\%) women were classified as having metabolic syndrome. $47.1 \%$ of women with (gestational) diabetes mellitus or women with glucose lowering medication in pregnancy developed metabolic syndrome six years later. The prevalence of metabolic syndrome in women with diabetes mellitus and/or glucose or cholesterol lowering medication at follow-up was $68.2 \%$. Compared to women without metabolic syndrome, women with metabolic syndrome six years after pregnancy had a more atherogenic plasma lipid profile in early pregnancy, significant for all analyzed lipids $(P$-value $<.001)$ (Table 2$)$.

Table 3 shows the association between maternal lipid levels in early pregnancy with metabolic syndrome six years after pregnancy. Women with higher levels of total cholesterol, triglycerides, LDL-c, remnant cholesterol and non-HDL-c levels in early pregnancy were more at risk of developing metabolic syndrome six years after pregnancy. These associations remained statistically significant after adjustment for confounders. HDL-c was negatively and independently associated with metabolic syndrome.

Figure 2 shows that compared to total cholesterol and LDL-c levels in the lower quartile, those in the highest quartile were associated with an increased risk of metabolic syndrome (OR 2.13, 95\% CI [1.52 to 2.99 ] and OR 2.20, 95\% CI [1.58 to 3.06], respectively). Compared to HDL-c levels in the highest quartile, those in the lower quartiles were associated with an increased risk of metabolic syndrome, with the highest risk for women in the lowest quartile (OR 7.91, 95\% CI [5.09 to 12.29]). Compared to triglycerides and remnant cholesterol levels in the lowest quartile, early pregnancy levels in the second, third and fourth quartile were associated with an increased risk of metabolic syndrome $(P$-value for trend analysis $<$.001). Women with triglyceride and remnant cholesterol levels in the highest quartile had the highest risk of metabolic syndrome (OR 13.61, 95\% CI [8.02 to 23.10] and OR 13.46, 95\% CI [7.93 to 22.85], respectively). Compared to non-HDL-c levels in the lowest quartile, early pregnancy non-HDL-c levels in the

Table 3 Association of maternal lipid levels in early pregnancy with metabolic syndrome six years after pregnancy $(n=3510)$

\begin{tabular}{|c|c|c|c|}
\hline & $\begin{array}{l}\text { Without metabolic syndrome } \\
n=3160\end{array}$ & $\begin{array}{l}\text { With metabolic syndrome } \\
\text { OR }(95 \% \mathrm{Cl}) \\
n=350\end{array}$ & $P$-value \\
\hline Total cholesterol, SDS & Reference & $1.30(1.16$ to 1.45$)$ & $<0.001$ \\
\hline Triglycerides, SDS & Reference & 2.43 (2.14 to 2.75$)$ & $<0.001$ \\
\hline LDL-c, SDS & Reference & $1.36(1.22$ to 1.51$)$ & $<0.001$ \\
\hline $\mathrm{HDL}-\mathrm{C}, \mathrm{SDS}$ & Reference & 0.51 (0.46 to 0.58$)$ & $<0.001$ \\
\hline Remnant cholesterol, SDS & Reference & 2.43 (2.14 to 2.76$)$ & $<0.001$ \\
\hline Non-HDL-c, SDS & Reference & 1.66 (1.49 to 1.86$)$ & $<0.001$ \\
\hline
\end{tabular}

Values are odds ratios (95\% confidence interval) derived from multiple logistic regression analyses. Basic model: adjusted for maternal age, gestational age at blood sampling, ethnicity, educational level, parity, smoking and folic acid supplementation. Abbreviations: SDS, SD-scores; Cl, confidence interval; OR, odds ratio; LDL-c, low-density lipoprotein cholesterol; HDL-c, high-density lipoprotein cholesterol 

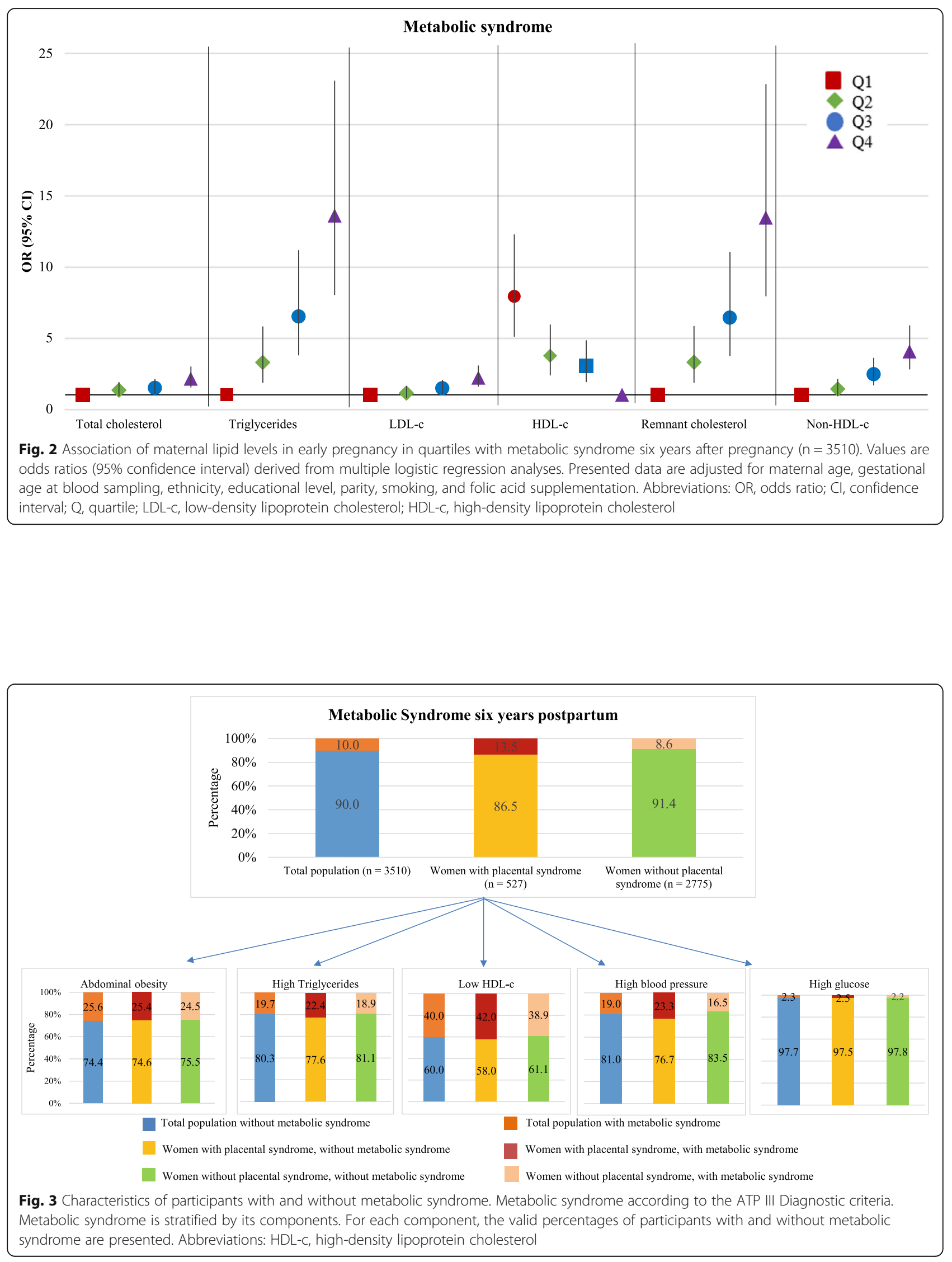
third and fourth quartile were associated with an increased risk of metabolic syndrome, with the highest risk for women in the highest quartile (OR 4.05, 95\% CI $[2.79$ to 5.88$])$.

\section{Metabolic syndrome and its components}

The most common feature of metabolic syndrome was low HDL-c (40.0\%) followed by abdominal obesity (25.6\%), high triglycerides (19.7\%), a high blood pressure (19.0\%), and high glucose levels (2.3\%) (Fig. 3).

\section{Women without placental syndrome vs women with placental syndrome}

Of the 2775 women without a placental syndrome in their index pregnancy, 239 (8.6\%) were classified as having metabolic syndrome six years after their index pregnancy. The prevalence of individual MS components were comparable to those of the total population: lowHDL-c $38.9 \%$, abdominal obesity $24.5 \%$, high triglycerides $18.9 \%$, high blood pressure $16.5 \%$, and high glucose levels $2.2 \%$ (Fig. 3).

Of the 527 women with a placental syndrome in their index pregnancy, 71 (13.5\%) were classified as having metabolic syndrome six years after pregnancy. Their most common feature of metabolic syndrome was also low HDL-c (42.0\%) followed by abdominal obesity (25.4\%), a high blood pressure (23.3\%), high triglycerides (22.4\%), and high glucose levels (2.5\%) (Fig. 3).

Women with a placental syndrome had a higher risk (OR 1.55, 95\% CI [1.15 to 2.07]) to develop metabolic syndrome six years after pregnancy compared to women without a placental syndrome.

In addition, the results of our regression analyses were not influenced by placental syndrome since the results were comparable when the analyses were repeated in a subset of women without placental syndrome in their index pregnancy $(n=2775)$ (data not shown).

\section{Discussion}

This study shows that lipid levels in early pregnancy are positively associated with lipid levels and the prevalence of metabolic syndrome six years after pregnancy. These associations remained significant after correction for smoking and BMI.

Previous studies on lipid levels measured in pregnancy and later in life are mostly limited to measurements up to one year postpartum [16, 17, 32]. These studies show that lipid levels initially decrease in pregnancy followed by a gradual increase and peak at the end of the third trimester. Lipid levels decline to plateau at four months after the delivery [18]. Postpartum total cholesterol levels and LDL-c levels remain somewhat but are significantly higher than the levels measured before pregnancy. However, these studies do not report on the association of gestational lipid levels with lipid levels after pregnancy. A previous study performed within the Generation R study population found that lipid levels in early pregnancy increase moderately with advancing gestational age in the time-frame when lipids in this study were measured [20]. Results from this study show that lipid levels measured in early pregnancy may already be indicative for lipid levels six years later, independent of smoking and BMI. Since early pregnancy lipid levels are also associated with adverse pregnancy outcomes and blood pressure during and after pregnancy [20], measurement of lipid levels in early pregnancy may improve short and long-term health of women.

The prevalence of metabolic syndrome in our relatively young and highly educated population of women was $10.0 \%$. Data on prevalence of metabolic syndrome in young women is scarce. Notably it is much lower than the prevalence of $22-28 \%$ of metabolic syndrome observed in American women aged 30-49 years described in the National Health and Nutrition Examination Survey (NHANES) [33]. A possible explanation may be that their mean BMI was higher and that their educational level was lower which is associated with an increased risk of metabolic syndrome [34].

Previous studies assessed the prevalence of metabolic syndrome in women who experienced hypertensive disorders of pregnancy, however almost all of these studies lacked a control group. Within these populations some found that women with early-onset pre-eclampsia had a higher risk of developing metabolic syndrome [8], whereas others did not find such an association [35]. A Canadian study, consisting of 217 women, found that the prevalence of metabolic syndrome after one and three years after pregnancy was $18.2 \%$ and $21.9 \%$ in women with previous pre-eclampsia and 6.8 and $6.4 \%$ in women without pre-eclampsia [36]. The mean BMI in that study was higher compared to that in our study $(28.7 \mathrm{~kg} / \mathrm{m} 2$ and $26.3 \mathrm{~kg} / \mathrm{m} 2$ in women with and without pre-eclampsia compared to $24.4 \mathrm{~kg} / \mathrm{m} 2$ in our population), which may account for the higher incidence of MS.

We hypothesized that BMI would be the main risk factor driving the association between gestational lipids and the lipid profile six years after pregnancy. However, these associations remained significant also after adjusting for pre-pregnancy BMI. Lipid levels are partially determined by lifestyle factors, but also by genetics [37, 38]. A recent study found that in a healthy population of women LDL-c levels $\geq 99$ th percentile were in $45.5 \%$ of the cases explained by unfavorable genotypes or mutations associated with hypercholesterolemia [37]. Several other studies also found that genetic background has a large influence on lipid concentrations which may be the reason why these associations remain significant after 
adjusting for BMI [38-40]. This is interesting since it suggests that lipid levels have a certain level of stability; independent of lifestyle factors. Therefore, unfavorable lipid levels may be an early marker for future cardiovascular risk. In our population the majority of women remained in the same quartile in pregnancy and six years after pregnancy (data not shown), supporting this hypothesis. As shown in previous studies, women with a placental syndrome have an increased risk of metabolic syndrome and CVD later in life [41]. Therefore, we performed the same analyses in a subset of women without placental syndromes. This did not affect our results. We therefore hypothesize that our results may be explained by genetic inheritance and to a lesser extent by lifestyle or pregnancy-related factors. Unfortunately, the nature of our study did not allow further investigation of this genetic contribution.

In young, fertile women monitoring of lipid levels may be relevant due to the association with CVD later in life. Currently, guidelines of the American Heart Association and guidelines of the European Society of Cardiology do not advice to determine gestational lipid levels [42, 43]. However, in our opinion adding lipids to the routine blood measurements in early pregnancy may provide an opportunity to early identify women with an increased CVD risk profile. This may be beneficial for timely intervention and prevention of metabolic syndrome and subsequently possible CVD in later life. Especially as women are more prone to improve lifestyle during pregnancy [44].

\section{Strengths and limitations}

Strengths of our study are the prospective and structured data collection from early pregnancy onwards. We also have a large sample of 3510 women with blood samples six years after pregnancy available. Some limitations need to be considered. First, blood samples were obtained in a non-fasting state. However, according to the joint consensus statement from the European Atherosclerosis Society and the European Federation of Clinical Chemistry and Laboratory Medicine lipids and lipoproteins change minimally in response to normal food intake [45].

Second, pre-pregnancy BMI was self-reported. Nevertheless, pre-pregnancy BMI was strongly correlated with BMI measured in early pregnancy, which makes misclassification unlikely.

Third, waist circumference was only measured ten years after pregnancy. However, weight measured six years after pregnancy was highly correlated to weight measured ten years after pregnancy, as did BMI six and ten years after pregnancy (Pearson's correlation coefficients, r 0.91 and 0.91 , respectively $[P<.001])$. Therefore, we assumed that waist circumference ten years after pregnancy could be used as a proxy for waist circumference six years after pregnancy.

Finally, similar to other studies, the non-response six years after pregnancy may have led to selection of relatively healthy women, which may affect the generalizability of results to high-risk populations (Additional file 1: Table S2).

\section{Conclusion}

The gestational lipid profile is associated with the lipid profile and metabolic syndrome six years after pregnancy, independent of smoking and BMI. Having a more atherogenic gestational lipid profile may act as an early risk marker for CVD later in life. Therefore, monitoring and possibly even early intervention should be indicated in women with a more atherogenic gestational lipid profile to diminish the cardiovascular burden later in life.

\section{Supplementary Information}

The online version contains supplementary material available at https://doi. org/10.1186/s12916-020-01868-4.

Additional file 1: Table S1. Association of maternal lipid profile in early pregnancy with their corresponding lipid levels six years later $(n=3510)$. Table S2. Baseline characteristics of women with and without available lipid measurements six years after pregnancy.

Additional file 2. STROBE statement.

Abbreviations

ATP: Adult Treatment Panel; BMI: Body mass index; Cl: Confidence interval; CVD: Cardiovascular disease; DBP: Diastolic blood pressure; HDL-c: Highdensity lipoprotein cholesterol; LDL-c: Low-density lipoprotein cholesterol; MS: Metabolic syndrome; NCEP: National Cholesterol Education Program: OR: Odds ratio; SBP: Systolic blood pressure; SD: Standard deviation; SDS: Standard deviation scores; SGA: Small-for-gestational age; SPTB: Spontaneous preterm birth

\section{Acknowledgements}

For this study we acknowledge the contributions of the general practitioners, midwives, pharmacies, the Municipal Health Service in the area Rotterdam, hospitals in Rotterdam, the Stichting Trombosedienst and Artsenlaboratorium Rijnmond and the participation of all participants. The Erasmus Medical Centre conduct the Generation R study in close collaboration with the School of Law and the Faculty of Social Sciences of the Erasmus University.

\section{Authors' contributions}

MC Adank analyzed the data and wrote the article. L Benschop, SP van Streun and AM Smak Gregoor contributed to the design of the paper, analyses and assisted with writing of the article. MT Mulder, EAP Steegers, S Schalekamp-Timmermans and JE Roeters van Lennep contributed to the design of the paper, writing of the article, interpretation of the data, revisions and gave input at all stages of the study. The authors read and approved the final manuscript.

\section{Funding}

The financial support for the Generation R study was made possible by the Erasmus Medical Centre, Erasmus University Rotterdam and the Netherlands Organization for Health Research and Development, the Netherlands Organization for Scientific Research, the Ministry of Health, Welfare and Sport, and the Ministry of Youth and Families.

Availability of data and materials

Data requests can be made to the secretary of Generation $\mathrm{R}$. 


\section{Ethics approval and consent to participate}

Ethical approval for this study was obtained by the Medical Ethics Committee of the Erasmus University Medical Centre (Erasmus MC), Rotterdam, the Netherlands (MEC-2007-413). Written consent was obtained from all participants.

\section{Consent for publication}

Not applicable.

\section{Competing interests}

None declared.

\section{Author details}

${ }^{1}$ Department of Obstetrics and Gynaecology, Erasmus MC, University Medical Centre Rotterdam, Rotterdam, the Netherlands. ${ }^{2}$ Generation R Study Group, Erasmus MC, University Medical Centre Rotterdam, Rotterdam, The Netherlands. ${ }^{3}$ Department of General Medicine, Erasmus MC, University Medical Centre Rotterdam, PO Box 2040, 3000 CA Rotterdam, The Netherlands.

Received: 6 October 2020 Accepted: 23 November 2020

Published online: 23 December 2020

\section{References}

1. Williams D. Pregnancy: a stress test for life. Curr Opin Obstet Gynecol. 2003; 15(6):465-71.

2. Mito A, Arata N, Qiu D, Sakamoto N, Murashima A, Ichihara A, Matsuoka R, Sekizawa A, Ohya Y, Kitagawa M. Hypertensive disorders of pregnancy: a strong risk factor for subsequent hypertension 5 years after delivery. Hypertens Res. 2018;41(2):141-6.

3. Bergen NE, Schalekamp-Timmermans S, Roos-Hesselink J, Roeters van Lennep JE, Jaddoe WW, Steegers EAP. Hypertensive disorders of pregnancy and subsequent maternal cardiovascular health. Eur J Epidemiol. 2018;33(8): 763-71.

4. Marin R, Gorostidi M, Portal CG, Sanchez M, Sanchez E, Alvarez J. Long-term prognosis of hypertension in pregnancy. Hypertens Pregnancy. 2000;19(2): 199-209.

5. Chesley LC, Annitto JE, Cosgrove RA. The remote prognosis of eclamptic women. Sixth periodic report. Am J Obstet Gynecol. 1976;124(5):446-59.

6. Svensson A, Andersch B, Hansson L. Prediction of later hypertension following a hypertensive pregnancy. J Hypertens Suppl. 1983;1(2):94-6.

7. Bellamy L, Casas JP, Hingorani AD, Williams DJ. Pre-eclampsia and risk of cardiovascular disease and cancer in later life: systematic review and metaanalysis. BMJ. 2007;335(7627):974

8. Hooijschuur MCE, Ghossein-Doha C, Kroon AA, De Leeuw PW, Zandbergen AAM, Van Kuijk SMJ, Spaanderman MEA. Metabolic syndrome and preeclampsia. Ultrasound Obstet Gynecol. 2019;54(1):64-71.

9. Sattar N, Greer IA. Pregnancy complications and maternal cardiovascular risk: opportunities for intervention and screening? BMJ. 2002;325(7356):157-60.

10. Wilson BJ, Watson MS, Prescott GJ, Sunderland S, Campbell DM, Hannaford $P$, Smith WC. Hypertensive diseases of pregnancy and risk of hypertension and stroke in later life: results from cohort study. BMJ. 2003;326(7394):845.

11. Hauspurg A, Countouris ME, Catov JM. Hypertensive disorders of pregnancy and future maternal health: how can the evidence guide postpartum management? Curr Hypertens Rep. 2019;21(12):96.

12. Brizzi P, Tonolo G, Esposito F, Puddu L, Dessole S, Maioli M, Milia S. Lipoprotein metabolism during normal pregnancy. Am J Obstet Gynecol. 1999;181(2):430-4.

13. Emet T, Ustuner I, Guven SG, Balik G, Ural UM, Tekin YB, Senturk S, Sahin FK, Avsar AF. Plasma lipids and lipoproteins during pregnancy and related pregnancy outcomes. Arch Gynecol Obstet. 2013;288(1):49-55.

14. Mazurkiewicz JC, Watts GF, Warburton FG, Slavin BM, Lowy C, Koukkou E. Serum lipids, lipoproteins and apolipoproteins in pregnant non-diabetic patients. J Clin Pathol. 1994;47(8):728-31.

15. Herrera E. Lipid metabolism in pregnancy and its consequences in the fetus and newborn. Endocrine. 2002;19(1):43-55.

16. Chiang AN, Yang ML, Hung JH, Chou P, Shyn SK, Ng HT. Alterations of serum lipid levels and their biological relevances during and after pregnancy. Life Sci. 1995;56(26):2367-75.

17. Grimes SB, Wild R. Effect of pregnancy on lipid metabolism and lipoprotein levels; 2000
18. Wiznitzer A, Mayer A, Novack V, Sheiner E, Gilutz H, Malhotra A, Novack L. Association of lipid levels during gestation with preeclampsia and gestational diabetes mellitus: a population-based study. Am J Obstet Gynecol. 2009;201(5):482 e481-488.

19. Enquobahrie DA, Williams MA, Butler CL, Frederick IO, Miller RS, Luthy DA. Maternal plasma lipid concentrations in early pregnancy and risk of preeclampsia. Am J Hypertens. 2004;17(7):574-81.

20. Adank MC, Benschop L, Peterbroers KR, Smak Gregoor AM, Kors AW, Mulder MT, Schalekamp-Timmermans S, Roeters Van Lennep JE, Steegers EAP. Is maternal lipid profile in early pregnancy associated with pregnancy complications and blood pressure in pregnancy and long term postpartum? Am J Obstet Gynecol. 2019;221(2):150 e151-13.

21. Benschop L, Bergen NE, Schalekamp-Timmermans S, Jaddoe WW, Mulder MT, Steegers EAP, Roeters van Lennep JE. Maternal lipid profile 6 years after a gestational hypertensive disorder. J Clin Lipidol. 2018;12(2):428-36 e424.

22. Kooijman MN, Kruithof CJ, van Duijn CM, Duijts L, Franco OH, van IJzendoorn MH, de Jongste JC, Klaver CC, van der Lugt A, Mackenbach JP, et al. The generation R study: design and cohort update 2017. Eur J Epidemiol. 2016;31(12):1243-64.

23. von Elm E, Altman DG, Egger M, Pocock SJ, Gotzsche PC, Vandenbroucke $J P$, Initiative $S$. The strengthening the reporting of observational studies in epidemiology (STROBE) statement: guidelines for reporting observational studies. J Clin Epidemiol. 2008;61(4):344-9.

24. Kruithof CJ, Kooijman MN, van Duijn CM, Franco OH, de Jongste JC, Klaver CC, Mackenbach JP, Moll HA, Raat H, Rings EH, et al. The generation R study: biobank update 2015. Eur J Epidemiol. 2014;29(12):911-27.

25. Friedewald WT, Levy RI, Fredrickson DS. Estimation of the concentration of low-density lipoprotein cholesterol in plasma, without use of the preparative ultracentrifuge. Clin Chem. 1972;18(6):499-502.

26. El Assaad MA, Topouchian JA, Darne BM, Asmar RG. Validation of the Omron HEM-907 device for blood pressure measurement. Blood Press Monit. 2002;7(4):237-41.

27. Expert Panel on Detection E, Treatment of High Blood Cholesterol in A. Executive summary of the third report of the National Cholesterol Education Program (NCEP) expert panel on detection, evaluation, and treatment of high blood cholesterol in adults (adult treatment panel III). JAMA. 2001;285(19):2486-97.

28. Coolman M, de Groot CJ, Jaddoe WW, Hofman A, Raat H, Steegers EA. Medical record validation of maternally reported history of preeclampsia. J Clin Epidemiol. 2010;63(8):932-7.

29. Brown MA, Lindheimer MD, de Swiet M, Van Assche A, Moutquin JM. The classification and diagnosis of the hypertensive disorders of pregnancy: statement from the International Society for the Study of Hypertension in Pregnancy (ISSHP). Hypertens Pregnancy. 2001;20(1):IX-XIV.

30. Sterne JA, White IR, Carlin JB, Spratt M, Royston P, Kenward MG, Wood AM, Carpenter JR. Multiple imputation for missing data in epidemiological and clinical research: potential and pitfalls. BMJ. 2009;338:b2393.

31. Graham JW, Olchowski AE, Gilreath TD. How many imputations are really needed? Some practical clarifications of multiple imputation theory. Prev Sci. 2007;8(3):206-13.

32. Parikh NI, Laria B, Nah G, Singhal M, Vittinghoff E, Vieten C, Stotland N, Coleman-Phox K, Adler N, Albert MA, et al. Cardiovascular disease-related pregnancy complications are associated with increased maternal levels and trajectories of cardiovascular disease biomarkers during and after pregnancy. J Women's Health (Larchmt). 2020;29(10):1283-91. PMID: 31934809. PMCID: PMC7583330. https://doi.org/10.1089/jwh.2018.7560.

33. Moore JX, Chaudhary N, Akinyemiju T. Metabolic syndrome prevalence by race/ethnicity and sex in the United States, National Health and nutrition examination survey, 1988-2012. Prev Chronic Dis. 2017;14:E24.

34. Wamala SP, Lynch J, Horsten M, Mittleman MA, Schenck-Gustafsson K, OrthGomer K. Education and the metabolic syndrome in women. Diabetes Care. 1999;22(12):1999-2003.

35. Veerbeek JH, Hermes W, Breimer AY, van Rijn BB, Koenen SV, Mol BW, Franx A, de Groot CJ, Koster MP. Cardiovascular disease risk factors after earlyonset preeclampsia, late-onset preeclampsia, and pregnancy-induced hypertension. Hypertension. 2015;65(3):600-6.

36. Smith GN, Pudwell J, Walker M, Wen SW. Risk estimation of metabolic syndrome at one and three years after a pregnancy complicated by preeclampsia. J Obstet Gynaecol Can. 2012;34(9):836-41.

37. Balder JW, Rimbert A, Zhang X, Viel M, Kanninga R, van Dijk F, Lansberg $P$, Sinke R, Kuivenhoven JA. Genetics, lifestyle, and low-density lipoprotein 
cholesterol in young and apparently healthy women. Circulation. 2018; 137(8):820-31.

38. Hamsten A, Iselius L, Dahlen G, de Faire U. Genetic and cultural inheritance of serum lipids, low and high density lipoprotein cholesterol and serum apolipoproteins A-I, A-II and B. Atherosclerosis. 1986;60(3):199-208.

39. Fuentes RM, Notkola IL, Shemeikka S, Tuomilehto J, Nissinen A. Familial aggregation of serum total cholesterol: a population-based family study in eastern Finland. Prev Med. 2000;31(5):603-7.

40. Kathiresan S, Musunuru K, Orho-Melander M. Defining the spectrum of alleles that contribute to blood lipid concentrations in humans. Curr Opin Lipidol. 2008;19(2):122-7.

41. Ray JG, Vermeulen MJ, Schull MJ, Redelmeier DA. Cardiovascular health after maternal placental syndromes (CHAMPS): population-based retrospective cohort study. Lancet. 2005;366(9499):1797-803.

42. Authors/Task Force M, Piepoli MF, Hoes AW, Agewall S, Albus C, Brotons C, Catapano AL, Cooney MT, Corra U, Cosyns B, et al. 2016 European Guidelines on cardiovascular disease prevention in clinical practice: The Sixth Joint Task Force of the European Society of Cardiology and Other Societies on Cardiovascular Disease Prevention in Clinical Practice (constituted by representatives of 10 societies and by invited experts): Developed with the special contribution of the European Association for Cardiovascular Prevention \& Rehabilitation (EACPR). Eur J Prev Cardiol. 2016; 23(11):NP1-NP96.

43. Bushnell C, McCullough LD, Awad IA, Chireau MV, Fedder WN, Furie KL, Howard VJ, Lichtman JH, Lisabeth LD, Pina IL, et al. Guidelines for the prevention of stroke in women: a statement for healthcare professionals from the American Heart Association/American Stroke Association. Stroke. 2014;45(5):1545-88.

44. Lindqvist M, Lindkvist M, Eurenius E, Persson M, Mogren I. Change of lifestyle habits - motivation and ability reported by pregnant women in northern Sweden. Sex Reprod Healthc. 2017;13:83-90.

45. Nordestgaard BG, Langsted A, Mora S, Kolovou G, Baum H, Bruckert E, Watts GF, Sypniewska G, Wiklund O, Boren J, et al. Fasting is not routinely required for determination of a lipid profile: clinical and laboratory implications including flagging at desirable concentration cut-points-a joint consensus statement from the European atherosclerosis society and European Federation of Clinical Chemistry and Laboratory Medicine. Eur Heart J. 2016; 37(25):1944-58.

\section{Publisher's Note}

Springer Nature remains neutral with regard to jurisdictional claims in published maps and institutional affiliations.

\section{Ready to submit your research? Choose BMC and benefit from:}

- fast, convenient online submission

- thorough peer review by experienced researchers in your field

- rapid publication on acceptance

- support for research data, including large and complex data types

- gold Open Access which fosters wider collaboration and increased citations

- maximum visibility for your research: over $100 \mathrm{M}$ website views per year

At $\mathrm{BMC}$, research is always in progress.

Learn more biomedcentral.com/submissions 